\title{
Cardiometabolic outcomes in children and adolescents with West syndrome
}

\author{
Inbar Gilboa ${ }^{1,2 \dagger}$, Galit Israeli ${ }^{1,2 \dagger}$, Avivit Brener ${ }^{1,2}$, Michal Yackobovitch-Gavan³, Uri Kramer ${ }^{2,4}$, \\ Shimrit Uliel-Sibony ${ }^{2,4}$ and Yael Lebenthal ${ }^{1,2^{*}}$ (i)
}

\begin{abstract}
Background: West syndrome is a convulsive disorder of infancy with unique seizures and a characteristic background electroencephalograph pattern. Adrenocorticotropic hormone (ACTH) is effective in spasm cessation, yet metabolic consequences of this therapeutic agent in childhood have not been published.

Methods: In this observational study we explored the cardiometabolic outcomes of 117 children with West syndrome (78 ACTH-treated and 39 non-ACTH-treated) monitored at a single medical center from 1995 to 2019 (median follow-up 7.2 years). Outcomes included the prevalence of cardiometabolic derangements (obesity, hypertension, and dyslipidemia) during infancy ( $<2$ years), early childhood ( $2-6$ years), and childhood/adolescence (6-18 years).

Results: The rates of metabolic derangements during infancy in the West syndrome cohort were high compared to childhood/adolescence (obesity $27.3 \%$ vs. $3.3 \%$, [ $p=0.010$ ], diastolic hypertension $48.8 \%$ vs. $5.1 \%$ [ $p<0.001]$, hypertriglyceridemia $71 \%$ vs. $40 \%$ [ $p=0.008]$, low high-density lipoprotein cholesterol [HDL-c] $54.2 \%$ vs. $12.9 \%$ $[p=0.001]$, and elevated triglycerides/HDL-c ratios $62.5 \%$ vs. $12.9 \%[p<0.001])$. The proportion of systolic and/or diastolic blood pressure levels categorized as hypertensive was $58.5 \%$ during infancy, $48.1 \%$ during early childhood, and $26.3 \%$ during childhood/adolescence. ACTH-treated patients had higher weight and weight-tolength z-scores and higher triglyceride levels during infancy compared to non-ACTH-treated patients $(p=0.008, p=$ 0.001 , and $p=0.037$, respectively), and higher triglyceride levels during early childhood $(p=0.050)$, with no significant group differences during childhood/adolescence.

Conclusions: Children with West syndrome apparently have an increased prevalence of cardiometabolic derangements more pronounced in infants and in ACTH-treated patients. These findings highlight the need to monitor these children for cardiometabolic derangements, even though these cardiometabolic abnormalities are transitory and tend to decrease with time. The health implications of cardiometabolic derangements during critical windows of growth and development warrant further investigation.
\end{abstract}

Keywords: Adrenocorticotropic hormone (ACTH), Dyslipidemia, Hypertension, Infantile spasms, Metabolic outcomes, Obesity

\footnotetext{
* Correspondence: yael.lebenthal@gmail.com; yaelleb@tlvmc.gov.il

${ }^{+}$Inbar Gilboa and Galit Israeli contributed equally to this study.

'Pediatric Endocrinology and Diabetes Unit, Dana-Dwek Children's Hospital,

Tel Aviv Sourasky Medical Center, 6423906 Tel Aviv, Israel

${ }^{2}$ Sackler Faculty of Medicine, Tel Aviv University, Tel Aviv, Israel

Full list of author information is available at the end of the article
}

(c) The Author(s). 2021 Open Access This article is licensed under a Creative Commons Attribution 4.0 International License, which permits use, sharing, adaptation, distribution and reproduction in any medium or format, as long as you give appropriate credit to the original author(s) and the source, provide a link to the Creative Commons licence, and indicate if changes were made. The images or other third party material in this article are included in the article's Creative Commons licence, unless indicated otherwise in a credit line to the material. If material is not included in the article's Creative Commons licence and your intended use is not permitted by statutory regulation or exceeds the permitted use, you will need to obtain permission directly from the copyright holder. To view a copy of this licence, visit http://creativecommons.org/licenses/by/4.0/ The Creative Commons Public Domain Dedication waiver (http://creativecommons.org/publicdomain/zero/1.0/) applies to the data made available in this article, unless otherwise stated in a credit line to the data. 


\section{Background}

West syndrome is a convulsive disorder of infancy, that may result from various etiologies, characterized by the combination of epileptic spasms (infantile spasms) and a characteristic electroencephalograph (EEG) pattern ("hypsarrhythmia"), as well as subsequent or concurrent arrest of psychomotor development [1-5]. Seizure onset is usually within the first year of life, with a peak at age 3-5 months [1]. The incidence of West syndrome is 0.16-0.42 per 1000 live births [1]. The seizures are often refractory to treatment with most conventional antiepileptic drugs $[1,6]$.

In 2009, the U.S. Food and Drug Administration approved adrenocorticotropic hormone $(\mathrm{ACTH})$ and vigabatrin as the first line of therapy for West syndrome, and in 2012 evidence-based updated practice guidelines indicated no clear preference of $\mathrm{ACTH}$ and vigabatrin [7], with the exception of children who had underlying tuberous sclerosis, for which vigabatrin was the reported treatment of choice $[1,5]$. The proposed mechanisms of action of ACTH therapy in infantile spasms are the reduction of neuronal excitability by inducing steroid release and/or by direct steroid-independent action on melanocortin receptors [8], as well as suppression of corticotropin-releasing hormone, an excitant neuropeptide [4]. There is no precise therapeutic protocol for ACTH, but most of the evidence suggests 2 weeks of treatment followed by dose tapering $[5,9]$.

Hormonal treatment with ACTH and corticosteroids may result in acute to subacute marked metabolic changes, such as weight gain, inhibition of growth, elevated blood pressure (BP), and insulin resistance [10, 11]. To date, there have been no published reports on the long-term evolution of these metabolic derangements associated with this therapeutic agent in the treatment of West syndrome. The objectives of this study were to describe the cardiometabolic characteristics in patients with West syndrome from infancy to childhood/adolescence, and to determine whether they differ among patients treated with ACTH during infancy compared to those not treated with ACTH.

\section{Methods}

This observational real-life study of children and adolescents with a history of West syndrome was based upon data collected from medical records of all patients treated in our Epilepsy Center from 1995 to 2019. The study protocol was approved by our Institutional Review Board, which waived informed consent of the participants since the data retrieved from the medical records were anonymous to the researchers. The data were handled in accordance with the principles of good clinical practice.
The study population was comprised of 117 patients with West syndrome classified according to treatment regimen (ACTH and no $\mathrm{ACTH}$ therapy) and the revised International League Against Epilepsy classification (structural, metabolic, genetic, or unknown) [12] (Fig. 1). Included in the study were children and adolescents diagnosed with West syndrome during infancy (aged 3-24 months) that was confirmed by epileptic spasms and a characteristic EEG pattern of hypsarrhythmia [1, 3]. Excluded from the study were 2 patients treated with pulse steroids in the non-ACTH group, and 5 patients whose data on the administered therapy were unclear.

In our center, ACTH is the first-line therapy in West syndrome, with the exception of cases of tuberous sclerosis and some selected cases of infants with a suspected structural, metabolic or genetic cause. The parents were made aware of the ACTH treatment protocol, the therapeutic course and the potential adverse effects. Vigabatrin was always the first-line therapy in patients with an underlying etiology of tuberous sclerosis. The therapeutic protocol for ACTH used at our institution was high-dose intramuscular tetracosactide (Synacthen Depot $^{\oplus}$, Novartis) 120 to $150 \mathrm{IU} / \mathrm{m}^{2} /$ dose given on alternate days for 1-2 weeks followed by dose tapering. Treatment failure was defined when ACTH treatment failed after 2 weeks of the high-dose protocol.

Outcome measures included anthropometric parameters (weight, length/height, and weight-to-length/BMI zscores), and prevalence of cardiometabolic derangements (obesity, hypertension, and dyslipidemia [hypertriglyceridemia, low levels of high-density lipoprotein cholesterol (HDL-c) and elevated triglyceride to HDL-c ratio]) at 3 time points: infancy ( $<2$ years), early childhood $(2-$ 6 years), and childhood/adolescence (6-18 years). The patient's anthropometric and metabolic data during infancy was extracted at least 2 months following ACTH cessation.

The information in the medical files contained both parent-reported information and physicians' notes on diagnoses, management, and surveillance. Paper-based medical files were used prior to 2000, after which all hospital medical records gradually became electronic, with additional access to the individual's health maintenance organization (HMO) laboratory data since 2007. The retrieved information included sociodemographic characteristics (age at last hospital visit, sex, country of origin, socioeconomic position [SEP] by home address), and West syndrome-related characteristics (conception [spontaneous/assisted], prenatal and perinatal history (pregnancy [singleton/twin], delivery [vaginal/elective cesarean section/emergency cesarean section/vacuum extraction], APGAR score [1 and $5 \mathrm{~min}$ ], gestational age [weeks], birth weight [grams], corrected birth weight zscore, head circumference $[\mathrm{cm}]$, head circumference $\mathrm{z}$ - 


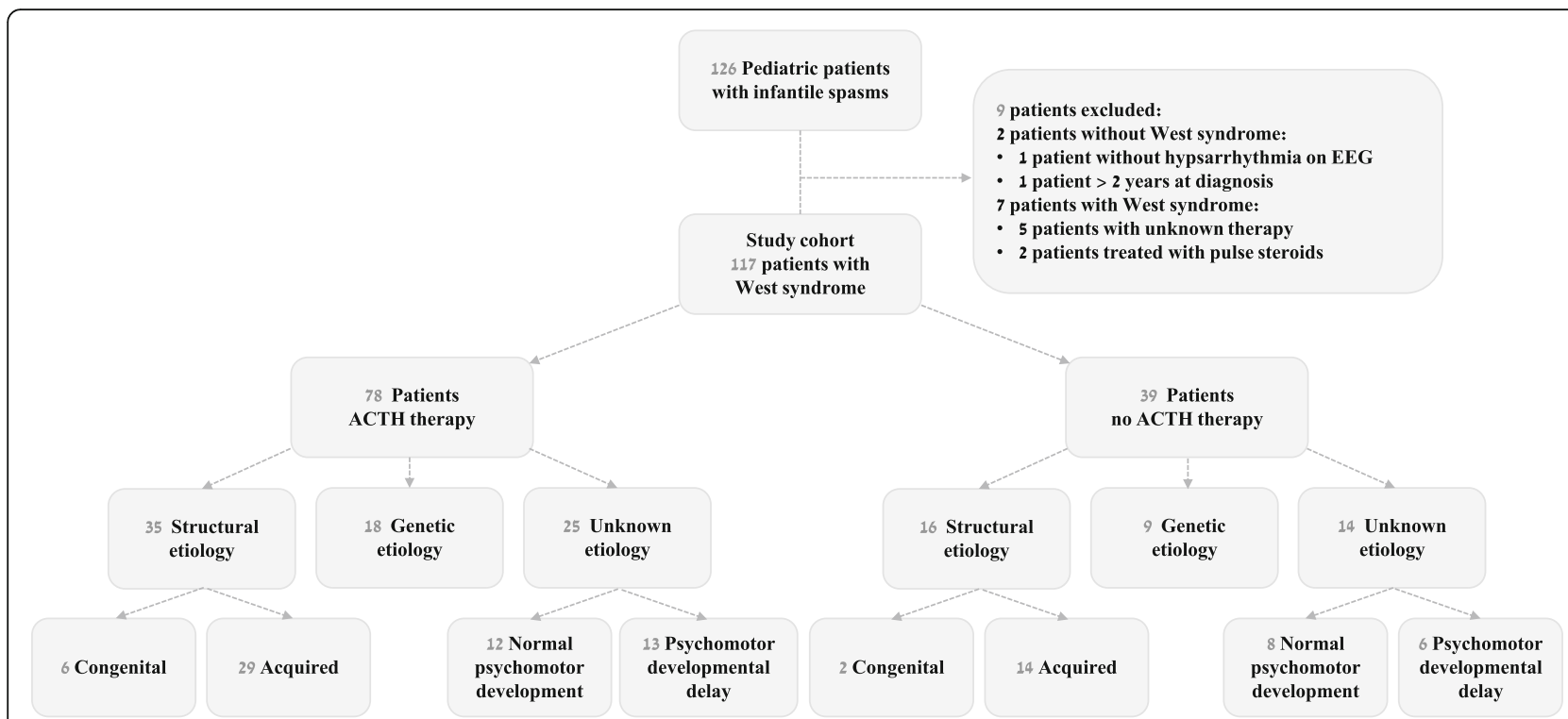

Fig. 1 The study population of 117 patients with West syndrome classified according to treatment regimen (ACTH and no ACTH therapy) and the revised International League Against Epilepsy classification. No patients were classified as being in the "metabolic etiology" group. Unknown etiology is subcategorized as with or without psychomotor developmental delay

score), age at diagnosis, etiology [structural/metabolic/ genetic/unknown], cerebral palsy [yes/no], gross motor function classification system, brain imaging [magnetic resonance imaging (MRI)/computed tomography $(\mathrm{CT})]$, psychomotor development [normal/mild delay/moderate delay/severe delay], and ACTH therapy and other medications). Psychomotor development was determined according to formal assessments by trained personnel from a child development institute, or by clinical evaluation of a pediatric neurologist. Cardiometabolic data included systolic and diastolic BP, anthropometric measurements (weight, length/height and calculated weightto-length/body mass index [BMI]), and laboratory evaluation (glucose and lipid profile [total cholesterol, triglycerides (TG), high-density lipoprotein (HDL-c)], and thyroid function tests [thyroid-stimulating hormone (TSH) and free thyroxine (fT4)]). The TG: HDL-c ratio was calculated [13]. Details on medications and dietary interventions that could affect anthropometric and cardiometabolic outcomes were also collected.

Z-scores of anthropometric measurements were calculated with PediTools Electronic Growth Chart Calculators, based on CDC growth charts, and those scores were adjusted for gestational age in preterm infants [14]. Z-scores of anthropometric measurements in patients with cerebral palsy were calculated with cerebral palsy-specific growth charts [15]. Weight status was categorized as underweight for weight-to-length/BMI values $<5$ th percentile, normal for weight-to-length/BMI between 5th and 84th percentiles, overweight for weight-to-length/BMI between 85th and 94th percentiles, and obese for weight-to-length/ $\mathrm{BMI} \geq 95$ th percentile [16]. Corrected birth weight $\mathrm{z}$ scores were calculated with PediTools Electronic Growth Chart Calculators based on the Fenton growth chart for preterm infants [14]. Appropriate for gestational age (AGA) birth weight was defined as corrected birth weight $\mathrm{z}$-scores of -1.88 to 1.88 , small for gestational age (SGA) as birth weight $\mathrm{z}$-scores $<-1.88$, and the large for gestational age (LGA) as birth weight $\mathrm{z}$-scores $>1.88$. BP percentiles were calculated by means of an online age-based pediatric BP calculator [17]. BP was defined as normal when $\mathrm{BP}$ values were $<90$ th percentile, elevated when either systolic and/or diastolic BP levels were from the $\geq$ 90th to 95th percentile, and hypertensive when either the systolic and/or the diastolic BP level were $\geq 95$ th percentile [18]. Dyslipidemia was defined as a TG level $\geq 100 \mathrm{mg} /$ $\mathrm{dL}, \mathrm{HDL}-\mathrm{c} \leq 40 \mathrm{mg} / \mathrm{dL}$ or TG/HDL-c $\geq 3[19,20]$.

Ethnicity was defined as the birthplace of the parents or grandparents (if the parents were born in Israel) and categorized according to country or region. SEP was defined by home address according to the Israel Central Bureau of Statistics' Characterization and Classification of Statistical Areas within Municipalities and Local Councils by the Socio-Economic Level of the Population 2015 [21]. The SEP by cluster of localities of residence ranged from 1 to 10 ; with 1 being the lowest rating and 10 the highest. The SEP index is an adjusted calculation of 14 variables that measure social and economic levels in the domains of demographics, education, standard of living, and employment (ranging from -2.797 to 2.590 ). 


\section{Statistical Analyses}

The data were analyzed with Statistical Package for the Social Sciences software version 27 (SPSS Inc., Chicago, IL). All statistical tests were 2-sided. The KolmogorovSmirnov test and the Shapiro-Wilk test were applied to test the normality of continuous data. The data are expressed as means \pm standard deviations (SDs) for normally distributed variables and median and interquartile range (IQR) for skewed distribution. Pearson's chisquare test or Fisher's exact test were performed to compare the distribution of categorical variables between the treatment groups (ACTH and non-ACTH) as appropriate. The independent sample $t$-test or independent sample Mann-Whitney were performed to compare between treatment groups for continuous variables with normal or skewed distribution, as appropriate. A 1-sample t-test was performed to test the null hypothesis that the participant's mean z-score equals zero. Univariate logistic regression analysis was applied to determine odds ratio $(\mathrm{OR})$ and $95 \%$ confidence interval $(\mathrm{CI})$ between $\mathrm{ACTH}$ therapy and cardiometabolic factors (BMI z-scores, systolic BP percentiles, diastolic BP percentiles, TG levels, HDL-c levels, and TG:HDL-c ratios). A $p$ value of $\leq 0.05$ was considered significant.

\section{Results}

The data on sociodemographic characteristics, maternal conditions during pregnancy and perinatal characteristics of the entire West syndrome cohort (117 patients, $53 \%$ males, mean age at diagnosis $6.4 \pm 3.5$ months) are presented in Table 1. The characteristics of the cohort stratified according to treatment group (ACTH-treated and non-ACTH-treated) are presented in Table 2. Sex, SEP and ethnic distribution did not differ between treatment groups. The distribution of residency differed between treatment groups: more ACTH-treated patients were Israeli residents compared to the non-ACTH-treated group $(p=0.043)$. The analyzed perinatal characteristics included maternal age, mode of conception, number of fetuses, mode of delivery, gestational age, adjusted birth weight, and birth weight categories, and they did not differ between treatment groups. Patients in the ACTHtreated group were characterized by higher rates of birth at term $(p=0.046)$ and larger adjusted head circumferences compared to those in the non-treated group albeit within the normal range $(p=0.005)$.

The West syndrome-related characteristics of our patients stratified by treatment group revealed that, on average, children in the ACTH-treated group were diagnosed at a younger age $(p=0.031)$ and had lower rates of psychomotor developmental delay $(p=0.040)$ compared to those in the non-treated group. Brain pathology on imaging, etiologic classification, and the proportion of patients with cerebral palsy did not differ between treatment groups, except for 5 patients in the non-ACTH-treated group who had tuberous sclerosis $(p<0.001)$.

Most of the West syndrome cohort (110 patients, $94 \%)$ received a variety of anti-epileptic agents over the course of the surveillance, and only 7 patients received ACTH alone. The antiepileptic medications known to affect cardiometabolic parameters were as follows: valproate in 76 patients (65\%), carbamazepine in 12 $(10.3 \%)$, and topiramate in 37 (31.6\%), with no statistically significant differences between the ACTH vs. the non-ACTH groups ( $59 \%$ vs. $76.9 \%, p=0.057,11.5 \%$ vs. $7.7 \%, p=0.524,30.8 \%$ vs. $33.3 \%, p=0.785$, respectively). Ketogenic diets were followed by 12 of the 91 Israeli patients (13.2\%): they included 11 of the 65 ACTH-treated patients (16.9\%) and 1 of the 26 nonACTH treated patients $(3.8 \%)(p=0.097)$. These data were not available in the medical files of the nonresidents.

\section{Cardiometabolic Outcome Measures}

Data on anthropometric measurements and laboratory evaluation of the West syndrome cohort stratified according to treatment group are presented in Table 3 . The mean age at last visit was $8.4 \pm 5.9$ years, with a median follow-up duration of 7.2 years (IQR 3.1-12.8). The mean weight and length $z$-scores during infancy were slightly below average $(-0.58 \pm 1.57, p=0.010$ and $0.37 \pm 1.10, \quad p=0.060$, respectively), while the mean weight-to-length $z$-score was within average $(0.29 \pm 1.78$, $p=0.384)$. The mean weight $\mathrm{z}$-score during early childhood was slightly below average $(-0.51 \pm 1.49, p=0.017)$, and the mean height and BMI z-scores were within average $(-0.05 \pm 1.32, p=0.810$ and $-0.15 \pm 1.14, p=0.452$, respectively). The mean weight, height, and BMI zscores during childhood and adolescence were within average $(0.08 \pm 1.44, p=0.681,-0.28 \pm 1.17, p=0.196$, and $-0.08 \pm 1.13, p=0.706$, respectively). Weight status categories during infancy, early childhood, and childhood/adolescence are presented in Fig. 2a. A relatively high proportion of patients were categorized as obese during infancy compared to childhood/adolescence $(27.3 \%$ vs. $3.3 \%, p=0.010)$.

The median systolic and diastolic BP percentiles were above average for all age groups, with a decrease over time. The median (IQR) systolic BP percentiles were 87 (66-98) in infancy, 82 (54-97) in early childhood, and 77 (55-94) in childhood/adolescence, and they tended to be higher in infancy compared to childhood/adolescence $(p=0.063)$. The median (IQR) diastolic BP percentiles were 94 (78-98.5) in infancy, 89 (60-99) in early childhood, and 59 (39-78) in childhood/adolescence, and were significantly higher in infancy than those for 
Table 1 Sociodemographic and perinatal characteristics of the West syndrome cohort

\begin{tabular}{|c|c|}
\hline Number & 117 \\
\hline Male sex, n (\%) & $62(53.0)$ \\
\hline Socioeconomic position* & $n=89$ \\
\hline Cluster & $6.0 \pm 2.4$ \\
\hline Index & $0.435 \pm 1.065$ \\
\hline Ethnicity, n (\%) & 111 \\
\hline Former Union of Soviet Socialist Republics & $31(27.9)$ \\
\hline North Africa & $26(23.4)$ \\
\hline Europe & $22(19.8)$ \\
\hline Mixed ethnicity & $23(20.7)$ \\
\hline Israeli Arab & $7(6.3)$ \\
\hline Other & $2(1.8)$ \\
\hline Maternal age at offspring birth, years & $29.8 \pm 5.3$ \\
\hline Maternal conditions during pregnancy, n (\%) & $n=82$ \\
\hline Healthy & $73(89.0)$ \\
\hline Hypercoagulability & $4(4.9)$ \\
\hline Gestational diabetes mellitus & $3(3.7)$ \\
\hline Hypothyroidism & $1(1.2)$ \\
\hline Inflammatory bowel disease & $1(1.2)$ \\
\hline Mode of conception, n (\%) & $n=83$ \\
\hline Spontaneous & $79(95.2)$ \\
\hline Assisted fertilization & $4(4.8)$ \\
\hline Pregnancy, n (\%) & $n=83$ \\
\hline Twin & $11(13.3)$ \\
\hline Intrauterine growth, n (\%) & $n=54$ \\
\hline Intrauterine growth retardation & $4(7.4)$ \\
\hline Mode of delivery, n (\%) & $n=74$ \\
\hline Vaginal & $44(59.5)$ \\
\hline Cesarean section, elective & $15(20.3)$ \\
\hline Cesarean section, emergency & $11(14.9)$ \\
\hline Vacuum extraction & $4(5.4)$ \\
\hline Gestational age & $n=85$ \\
\hline Gestational age, weeks & $39(36-40)$ \\
\hline Preterm, < 37 weeks gestation, $n(\%)$ & $25(29.4)$ \\
\hline Term, 38-42 weeks gestation, $\mathrm{n}(\%)$ & $54(63.5)$ \\
\hline Postterm, > 42 weeks gestation, $n(\%)$ & $6(7.1)$ \\
\hline Newborn & $n=78$ \\
\hline APGAR score, $1 \mathrm{~min}$ & $9(6-9)$ \\
\hline APGAR score, $5 \mathrm{~min}$ & $10(8-10)$ \\
\hline Birth parameters & $n=78$ \\
\hline Birth weight, z-score & $-0.33 \pm 0.95$ \\
\hline Small for gestational age, $\mathrm{n}(\%)$ & $5(6.4)$ \\
\hline Appropriate for gestational age, $\mathrm{n}(\%)$ & $72(92.3)$ \\
\hline Large for gestational age, $\mathrm{n}(\%)$ & $1(1.3)$ \\
\hline Head circumference, z-score & $-0.59 \pm 0.56$ \\
\hline
\end{tabular}

Data are expressed as number and (percent), mean \pm standard deviation, median (interquartile range). Socioeconomic position (SEP) was determined by cluster of localities of residence, ranging from 1 to 10; with 1 being the lowest rating and 10 the highest. The SEP index is an adjusted calculation of 14 variables that measure social and economic levels in the domains of demographics, education, standard of living, and employment (ranging from the lowest -2.797 to the highest 2.590). The ethnicity was defined as the birthplace of the parents or grandparents (if the parents were born in Israel) and categorized according to country or region. *Missing data: SEP ( $n=28$, tourist medicine from Russia and the Ukraine $[n=26]$ and Israeli residents with paper medical files [n=2]). Abbreviations: $A P G A R$, appearance pulse grimace activity respiration; $n$ number 
Table 2 Comparative analysis of the characteristics of 117 patients with West syndrome according to treatment group

\begin{tabular}{|c|c|c|c|}
\hline & ACTH treated & non-ACTH treated & $P$ value \\
\hline Number & 78 & 39 & \\
\hline Male sex, n (\%) & $42(53.8)$ & $20(51.3)$ & 0.799 \\
\hline Socioeconomic position & $n=64$ & $n=25$ & \\
\hline Cluster & $6.0 \pm 2.4$ & $5.9 \pm 2.3$ & 0.909 \\
\hline Index & $0.447 \pm 1.086$ & $0.406 \pm 1.031$ & 0.871 \\
\hline \multicolumn{4}{|l|}{ Residency status, n (\%) } \\
\hline Israeli & $65(83.3)$ & $26(66.7)$ & 0.043 \\
\hline Tourists & $13(16.7)$ & $13(33.3)$ & \\
\hline Gestational age & $n=66$ & $n=19$ & \\
\hline Gestational age, weeks & $39(36-40)$ & $39.5(28-41)$ & 0.560 \\
\hline Preterm < 37 weeks' gestation, n (\%) & $17(25.8)$ & $8(42.1)$ & 0.050 \\
\hline Term 38-42 weeks' gestation, n (\%) & $46(69.7)$ & $8(42.1)$ & \\
\hline Postterm > 42 weeks gestation, $\mathrm{n}(\%)$ & $3(4.5)$ & $3(15.8)$ & \\
\hline \multicolumn{4}{|l|}{ Birth parameters } \\
\hline Birth weight, z-score & $-0.34 \pm 0.94$ & $-0.27 \pm 1.02$ & 0.787 \\
\hline Head circumference, z-score & $-0.45 \pm 0.47$ & $-1.37 \pm 0.40$ & 0.005 \\
\hline \multicolumn{4}{|l|}{ West syndrome } \\
\hline Age at diagnosis, months & $5.9 \pm 3.0$ & $7.5 \pm 4.2$ & 0.031 \\
\hline Etiology, n (\%) & $n=78$ & $n=39$ & \\
\hline Unknown, normal development & $12(15.4)$ & $8(20.5)$ & 0.991 \\
\hline Unknown, developmental delay & $13(16.7)$ & $6(15.4)$ & \\
\hline Genetic syndrome & $18(23.1)$ & $9(23.1)$ & \\
\hline Structural, congenital & $6(7.7)$ & $2(5.1)$ & \\
\hline Structural, acquired & $29(37.2)$ & $14(35.9)$ & \\
\hline Metabolic & $0(0)$ & $0(0)$ & \\
\hline Brain imaging - MRI/CT, n (\%) & $n=72$ & $n=31$ & \\
\hline Normal & $14(19.4)$ & $5(16.1)$ & 0.693 \\
\hline Pathologic & $58(80.6)$ & $26(83.9)$ & \\
\hline Cerebral palsy, n (\%) & $26(33.3)$ & $13(33.3)$ & 1 \\
\hline Psychomotor development, n (\%) & $n=69$ & $n=29$ & \\
\hline Normal & $10(14.5)$ & $0(0)$ & 0.040 \\
\hline Mild developmental delay & $9(13)$ & $2(6.9)$ & \\
\hline Moderate developmental delay & $21(30.4)$ & $16(55.2)$ & \\
\hline Severe developmental delay & $29(42)$ & $11(37.9)$ & \\
\hline
\end{tabular}

Data are expressed as number and (percent), mean \pm standard deviation, median (interquartile range). Socioeconomic position (SEP) was determined by cluster of localities of residence, ranging from 1 to 10; with 1 being the lowest rating and 10 the highest. The SEP index is an adjusted calculation of 14 variables that measure social and economic levels in the domains of demographics, education, standard of living, and employment (ranging from the lowest - 2.797 to the highest 2.590). $P$ values are between the ACTH- and non-ACTH-treated groups. Bold indicates significant

* Maternal age at delivery was available for 41 mothers of infants in the ACTH-treated group and for 8 mothers in the non-ACTH treated group. Abbreviations: $A C T H$ adrenocorticotropic hormone; CT computed tomography; MRI magnetic resonance imaging; $n$ number

childhood/adolescence $(p<0.001)$. The BP categories during infancy, early childhood, and childhood/adolescence are presented in Fig. 2b\&c. The proportion of systolic and/or diastolic blood pressure levels categorized as hypertensive was $58.5 \%$ during infancy, $48.1 \%$ during early childhood, and $26.3 \%$ during childhood/ adolescence. Systolic BP levels categorized as hypertensive tended to be higher in infancy compared to childhood/adolescence ( $41.5 \%$ vs. $23.1 \%, p=0.080)$. Diastolic BP levels categorized as hypertensive were higher in infancy compared to childhood/adolescence $(48.8 \%$ vs. $5.1 \%, p<0.001)$. 
Table 3 Longitudinal anthropometric characteristics and laboratory evaluations of the West syndrome cohort categorized according to treatment

\begin{tabular}{|c|c|c|c|}
\hline & $\begin{array}{l}\text { ACTH treated } \\
n=78\end{array}$ & $\begin{array}{l}\text { non-ACTH treated } \\
n=39\end{array}$ & $P$ value \\
\hline \multicolumn{4}{|l|}{ Infancy, $0-2$ years } \\
\hline Age, years & $1.1 \pm 0.4$ & $1.3 \pm 0.3$ & 0.106 \\
\hline Anthropometric characteristics & $n=46$ & $n=7$ & \\
\hline Weight z-score & $-0.36 \pm 1.51$ & $-2.01 \pm 1.23$ & 0.008 \\
\hline Length z-score & $-0.42 \pm 1.17$ & $-0.05 \pm 0.48$ & 0.495 \\
\hline Weight-to-length z-score & $0.70 \pm 1.45$ & $-1.97 \pm 1.86$ & 0.001 \\
\hline $\mathrm{BP}$ measurements & $n=40$ & $n=7$ & \\
\hline Systolic BP percentile & $86.5(66.5-97.3)$ & $98.0(84.0-99.0)$ & 0.283 \\
\hline Diastolic BP percentile & $95.0(86.0-98.3)$ & $91.0(55.0-96.0)$ & 0.403 \\
\hline Laboratory evaluation & $n=58$ & $n=11$ & \\
\hline Glucose, mg/dL & $86.5(75.0-95.0)$ & $91.5(78.0-99.3)$ & 0.154 \\
\hline Triglycerides, mg/dL & $178.1 \pm 80.7$ & $108.6 \pm 40.3$ & 0.037 \\
\hline $\mathrm{HDL}-\mathrm{c}, \mathrm{mg} / \mathrm{dL}$ & $40.7 \pm 9.8$ & $44.3 \pm 14.3$ & 0.513 \\
\hline Triglycerides to $\mathrm{HDL}-\mathrm{c}$ ratio & $4.7 \pm 2.4$ & $2.7 \pm 1.0$ & 0.086 \\
\hline Early childhood, 2-6 years* & 74 & 39 & \\
\hline Age, years & $3.5 \pm 1.1$ & $4.2 \pm 1.1$ & 0.056 \\
\hline Anthropometric characteristics & $n=44$ & $\mathrm{n}=10$ & \\
\hline Weight z-score & $-0.58 \pm 1.64$ & $-0.21 \pm 0.49$ & 0.486 \\
\hline Height z-score & $-0.08 \pm 1.37$ & $0.06 \pm 1.22$ & 0.807 \\
\hline BMI z-score & $-0.17 \pm 1.25$ & $-0.07 \pm 0.68$ & 0.841 \\
\hline $\mathrm{BP}$ measurements & $n=35$ & $n=10$ & \\
\hline Systolic BP percentile & $82.0(67.5-97.5)$ & $68.0(29.8-87.3)$ & 0.333 \\
\hline Diastolic BP percentile & $92.0(66.0-99.0)$ & $72.0(52.0-91.5)$ & 0.333 \\
\hline Laboratory evaluation & $n=37$ & $n=9$ & \\
\hline Glucose, mg/dL & $85.3(80.3-94.5)$ & $89.0(83.0-108.5)$ & 0.266 \\
\hline Triglycerides, mg/dL & $138.6 \pm 61.0$ & $78.4 \pm 34.6$ & 0.050 \\
\hline $\mathrm{HDL}-\mathrm{c}, \mathrm{mg} / \mathrm{dL}$ & $42.0 \pm 11.1$ & $44.7 \pm 16.5$ & 0.735 \\
\hline Triglycerides to $\mathrm{HDL}-\mathrm{c}$ ratio & $3.9 \pm 2.7$ & $2.6 \pm 2.1$ & 0.455 \\
\hline Childhood and adolescence, 6-18 years* & $n=53$ & $n=35$ & \\
\hline Age, years & $11.1 \pm 3.4$ & $11.9 \pm 3.9$ & 0.410 \\
\hline Anthropometric characteristics & $n=45$ & $\mathrm{n}=15$ & \\
\hline Weight z-score & $0.27 \pm 1.43$ & $-0.51 \pm 1.37$ & 0.070 \\
\hline Height z-score & $-0.10 \pm 1.03$ & $-1.03 \pm 1.50$ & 0.082 \\
\hline BMI z-score & $0.05 \pm 0.98$ & $-0.58 \pm 1.60$ & 0.227 \\
\hline $\mathrm{BP}$ measurements & $n=40$ & $n=15$ & \\
\hline Systolic BP percentile & $77.5(56.8-91.5)$ & $65.0(34.0-98.5)$ & 0.999 \\
\hline Diastolic BP percentile & $58.0(37.5-79.0)$ & $60.0(42.0-69.5)$ & 0.659 \\
\hline Laboratory evaluation & $n=50$ & $n=21$ & \\
\hline Glucose, mg/dL & $90.0(80.9-98.0)$ & $85.0(80.0-97.0)$ & 0.459 \\
\hline Triglycerides, mg/dL & $100.2 \pm 52.9$ & $89.2 \pm 36.5$ & 0.485 \\
\hline $\mathrm{HDL}-\mathrm{c}, \mathrm{mg} / \mathrm{dL}$ & $54.6 \pm 16.1$ & $53.5 \pm 14.3$ & 0.872 \\
\hline Triglycerides to HDL-c ratio & $2.3 \pm 2.9$ & $1.9 \pm 0.6$ & 0.723 \\
\hline
\end{tabular}

Data are expressed as mean \pm standard deviation, median (interquartile range). $P$ values are between the ACTH/non-ACTH treated groups. ${ }^{*}$ Of note, 74 patients in the ACTH-treated group reached early childhood and 53 patients reached childhood/adolescence, while 35 patients in the non-ACTH treated group reached childhood/adolescence at the time of data collection. Bold indicates significant. Abbreviations: ACTH adrenocorticotropic hormone; BMI body mass index; BP blood pressure; HDL-c high-density lipoprotein cholesterol; $n$ number 


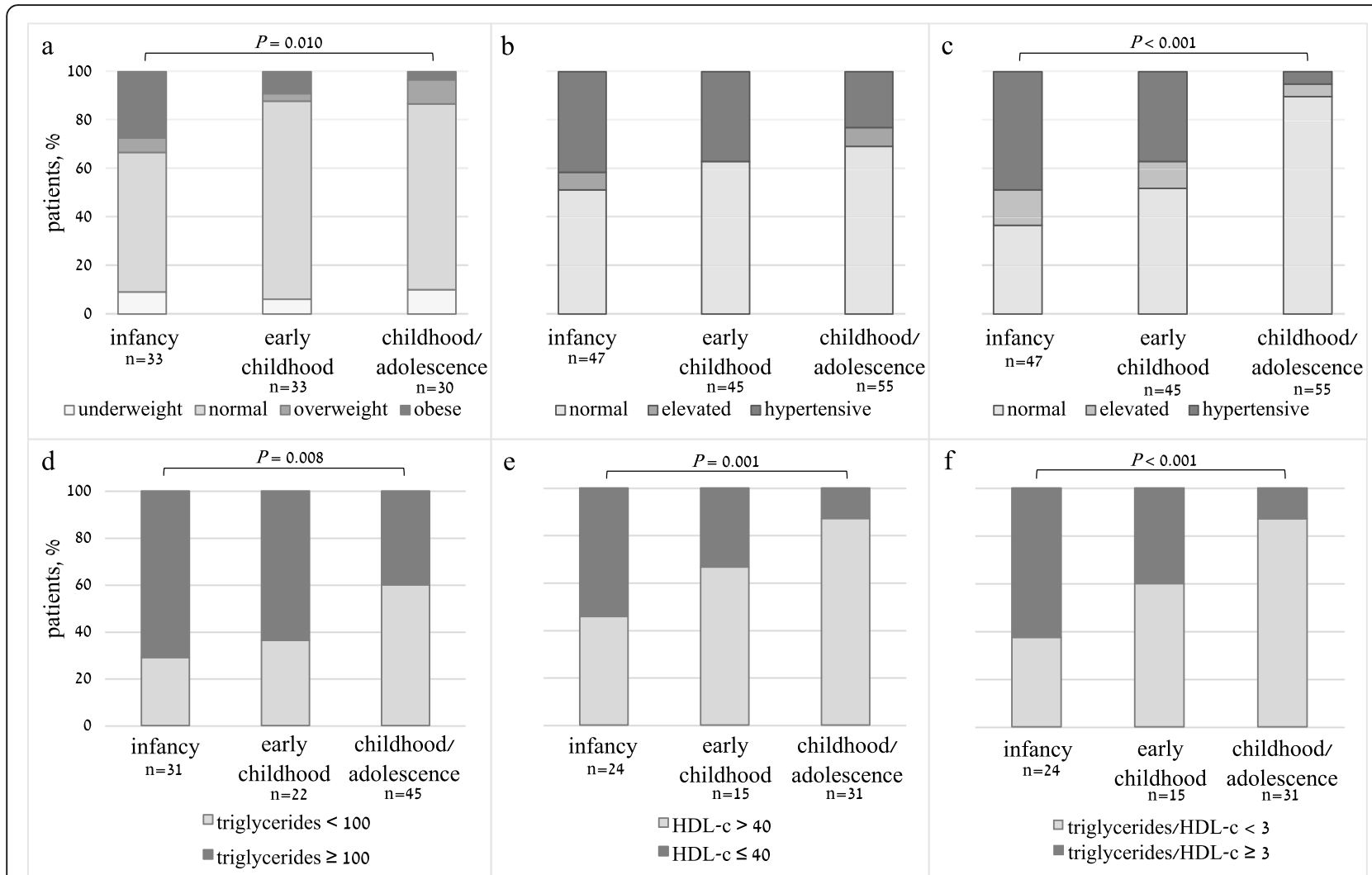

Fig. 2 Stacked column charts of the categorical representation of weight status (a), systolic (b) and diastolic (c) blood pressure, TG levels (d), HDLc levels (e) and triglyceride to HDL-c ratios in patients with West syndrome during infancy, early childhood, and childhood/adolescence. The proportion of patients with cardiometabolic derangements was higher in infancy compared to childhood/adolescence (obesity $P=0.010$, diastolic hypertension $P<0.001$, hypertriglyceridemia $P=0.008$, low HDL-c levels $P=0.001$, elevated TG/HDL-c ratios $P<0.001$ ). Abbreviations: TG triglycerides; HDL-c high-density lipoprotein cholesterol

The mean TG levels and TG/HDL-c ratios during infancy were elevated $(162.4 \pm 78.7 \mathrm{mg} / \mathrm{dL}$ and $4.3 \pm 2.3$, respectively). The mean TG/HDL-c were also elevated during early childhood and childhood/adolescence $(3.6 \pm 2.6$ and $2.2 \pm 2.6$, respectively). The mean TG levels and TG/HDL-c ratios were higher, while the mean HDL-c levels were lower in infancy compared to childhood/adolescence $(p<0.001, p=0.003$, and $p=0.001$, respectively). Categorical TG, HDL-c and TG:HDL-c levels during infancy, early childhood, and childhood/ adolescence are presented in Fig. 2d-f. The percentage of patients with dyslipidemia was higher in infancy compared to childhood/adolescence (hypertriglyceridemia $71 \%$ vs. $40 \%, p=0.008$; low HDL-c $54.2 \%$ vs. $12.9 \%$, $p=0.001$; elevated TG/HDL-c ratios $62.5 \%$ vs. $12.9 \%$, $p<0.001)$. The TSH and fT4 levels were within the normal range during infancy, early childhood, and childhood/adolescence, with no statistical difference between treatment groups.

During infancy, the ACTH-treated group had mean normal weight status parameters (weight and weight-tolength z-scores) which were significantly higher than those of the non-ACTH treated group $(p=0.008$ and $p=0.001$, respectively). In addition, they had significantly higher TG levels compared to the non-ACTHtreated group during both infancy and early childhood ( $p=0.037$ and $p=0.050$, respectively), with no significant differences between groups during childhood and adolescence. Univariate logistic analysis revealed that ACTH-treated patients had a significantly higher risk of increased BMI z-scores (OR 1.71, $95 \%$ CI 1.13-2.58, $p=0.011$ ), increased diastolic BP percentiles (OR for 10percentile increases $1.18,95 \%$ CI $1.01-1.39, p=0.040$ ) and increased TG (OR for each $10 \mathrm{mg} / \mathrm{dl}$ increase in TG $1.14,95 \%$ CI 1.04-1.26, $p=0.008)$, with no increased risk for elevated systolic BP percentiles, low HDL-c levels and elevated TG:HDL-c ratios.

\section{Discussion}

The cardiometabolic characteristics of patients with West syndrome from infancy through early childhood to childhood/adolescence have not been addressed. In this observational study, patients with West syndrome exhibited increased rates of obesity, elevated BP, and 
dyslipidemia (hypertriglyceridemia and elevated TG: HDL-c ratios). Infants with West syndrome who were treated with ACTH were characterized by higher weight and weight-to-length values, albeit within the normal range, and higher TG levels compared to infants with West syndrome who did not receive ACTH. These differences in metabolic characteristics between treatment groups became less evident during early childhood and childhood/adolescence.

Although the proportion of preterm births among our entire cohort was high relative to normal values, most of the pregnancies were uncomplicated and had followed spontaneous conception in healthy mothers, leading to appropriate birth weights and suggesting that the inutero environment was non-contributory. It would appear, therefore, that the weight gain during infancy and childhood was most likely related to exposure to postnatal factors. One-quarter of our study infants with West syndrome were categorized as being obese. Moreover, infants who received ACTH treatment weighed more and had normal adjusted weight-to-length ratios compared to those who were not treated with ACTH and were underweight. The lower weight status in the nonACTH treated group could stem from their medical complexity leading to poor oral intake. However, the finding that weight status during early childhood and during childhood and adolescence did not differ between the groups suggests that the ACTH treatment contributed to the weight gain observed in the ACTH-treated group during infancy, which masks their lower weight status. Weight gain in infants with West syndrome during the course of ACTH treatment which resolved following cessation of therapy has been reported in several studies [22, 23]. In contrast, weight gain was observed after the cessation of ACTH treatment in our study cohort. Preterm birth was more frequent in the children who did not receive ACTH treatment, but prematurity is a less plausible explanation for our finding since anthropometric measurements were adjusted for gestational age. Moreover, the differences in weight cannot be attributed to the underlying etiologies since the distribution was similar between treatment groups. Thyroid function was within the normal range, thereby not supporting it having any role in weight gain.

Hypertension (HTN) was observed in the majority of infants with West syndrome. Others have reported a link between preterm birth and elevated BP levels that had been detected as early as infancy [24, 25]. It is plausible that prematurity may contribute to the elevated BP levels observed in the current work, but it could not be the sole explanatory factor since only $~ 30 \%$ of the children were born preterm. Notably, although the vital signs were measured by registered nurses who specialize in pediatrics, it is possible that some of the measurements were spuriously elevated due to suboptimal conditions (crying toddlers, emergency room setting). ACTH therapy for the indication of infantile spasms has been reported to cause HTN [23, 26], but it could not be the sole cause of elevated BP observed in our study since BP levels were similar between the treatment groups. HTN was less evident in childhood and adolescence during which there was a normal distribution of diastolic BP values. BP was not monitored in all of the studied children, which may have led us to underestimate the incidence of HTN among children with West syndrome who had and had not been treated with ACTH. Despite significant concerns about side effects of ACTH therapy, including HTN and cardiomyopathy, there are no evidence-based guidelines to assist in the monitoring and management of these adverse effects.

Many of the patients in the current study had evidence of dyslipidemia; hypertriglyceridemia during infancy, as well as a high TG:HDL-c ratio from infancy through childhood/adolescence, although the dyslipidemia became less prominent over time. There is convincing evidence to suggest that the origins of atherosclerosis begin in childhood and that lipid abnormalities contribute to this process $[19,27]$. A high TG:HDL-c ratio is associated with arterial stiffness in children and adolescents [13], and it indicates an atherogenic lipid profile and predicts the risk for development of extensive coronary disease in adults $[28,29]$. Patients with epilepsy may exhibit dysregulation of thyroid functions which may impact serum lipid levels [30], however, thyroid functions were within the normal range and were unlikely to cause dyslipidemia among our study patients. Despite the efficacy of therapies, such as ACTH, many children with West syndrome will relapse and can develop other seizure types. As such, neurologists may consider selection of other anti-seizure medications and exploration of dietary interventions. Treatments that may be associated with hypertriglyceridemia include antiepileptic drugs (e.g., valproic acid, carbamazepine), and the ketogenic diet [31-33], and carbamazepine and other antiepileptic drugs have been associated with high HDL-c levels as well [31, 33]. Treatment of tuberous sclerosis complex with everolimus or sirolimus is a potential cause of dyslipidemia [34], however, none of the patients in the current study were treated with these drugs. Prematurity may also be associated with dyslipidemia later in life, but probably not with changes in triglyceride or HDL-c levels [24]. One study did find high TG levels in adolescent boys who were born preterm [35]. These explanations could account for some of our findings at best. TG levels were higher in infants and children treated with $\mathrm{ACTH}$, compared to those who were not. Taken together, these findings suggest a possible link between $\mathrm{ACTH}$ treatment and hypertriglyceridemia. 
The major limitations of this study are its retrospective nature and the relatively small sample size. Some of the data extracted from the medical files relied on the parent-reported information, such as perinatal history, and physicians documented, such as dosage and duration of the administered treatment. Yet, access to the patient's comprehensive HMO medical files contributed to the clinical and laboratory data, medications prescribed, and thus limits information bias. Moreover, growth parameters and cardiometabolic assessment were not available for the entire cohort, introducing ascertainment bias. Notably, more data were missing for the nonresident study participants who comprised the larger proportion of the group that had not received ACTH treatment. In addition, BP measurements were obtained in several different care settings without standardized methods.

Despite these limitations, our tertiary care center serves all sectors of the Israeli population including varied ethnic origins and socio-economic position, therefore this study should be representative of the Israeli population, apart from an under-representation of patients from the Arab sector.

In conclusion, our findings suggest that children with West syndrome have an increased prevalence of acute and subacute cardiometabolic derangements (obesity, HTN, and dyslipidemia), which are more pronounced during infancy and in ACTH-treated patients. An optimistic interpretation of our findings may be the transitory nature of the metabolic derangements. Still, they highlight the need to monitor these children at risk for cardiometabolic derangements, given that the origin of atherosclerosis begins in childhood and adolescence. The health implications in adulthood of cardiometabolic derangements during critical periods of growth and development have yet to be elucidated and warrant further investigation.

\section{Acknowledgements}

This work was performed by Inbar Gilboa in partial fulfilment of the MD thesis requirements of the Sackler Faculty of Medicine, Tel Aviv University, Tel Aviv, Israel. The authors wish to thank Esther Eshkol for editorial assistance.

\section{Guidelines}

All methods were carried out in accordance with relevant guidelines and regulations.

\section{Authors' contributions}

IG and GI made substantial contributions to the conception and design of the study, acquisition, analysis, and interpretation of data and drafting the initial manuscript. $A B$ made substantial contributions to the conception and design of the study, analysis, and interpretation of data and to revising it critically for important intellectual content. MYG made substantial contributions to the analysis and interpretation of the data and to revising it critically for important intellectual content. UK contributed to acquisition of the data used in this study, contributed to the discussion and reviewed and edited the manuscript. SUS contributed to acquisition and interpretation of the data used in this study, contributed to the discussion and reviewed and edited the manuscript. YL made substantial contributions to the conception and design of the study, the interpretation of data, drafting and revising it critically for important intellectual content. All authors gave final approval of the version to be published. YL is the guarantor of this work, and, as such, had full access to all the data in the study and takes responsibility for the integrity of the data and the accuracy of the data analysis.

Funding

No funding was received.

\section{Availability of data and materials}

The data used to support the findings of this study are available from the corresponding author upon request.

\section{Declarations}

\section{Ethics Approval}

The study was approved by the Ethics Committee of the Tel-Aviv Sourasky Medical Center according to the Helsinki Declaration. Informed consent by the participants was waived by the Ethics Committee of the Tel-Aviv Sourasky Medical Center since the data were retrieved from the subjects' medical records and all personal identification was omitted. The data were handled in accordance with the principles of Good Clinical Practice.

\section{Consent to Participate}

Informed consent of the participants was waived since the data retrieved from the medical records were anonymous to the researchers.

\section{Consent for Publication}

Not applicable.

\section{Competing interests}

The authors declare no conflicts of interest.

\section{Author details}

'Pediatric Endocrinology and Diabetes Unit, Dana-Dwek Children's Hospital, Tel Aviv Sourasky Medical Center, 6423906 Tel Aviv, Israel. ${ }^{2}$ Sackler Faculty of Medicine, Tel Aviv University, Tel Aviv, Israel. ${ }^{3}$ Department of Epidemiology and Preventive Medicine, School of Public Health, Sackler Faculty of Medicine, Tel Aviv University, Tel Aviv, Israel. ${ }^{4}$ Pediatric Neurology Institute, Dana-Dwek Children's Hospital, Tel Aviv Sourasky Medical Center, Tel Aviv, Israel.

Received: 28 April 2021 Accepted: 28 August 2021

Published online: 18 September 2021

\section{References}

1. Hancock EC, Osborne JP, Edwards SW. Treatment of infantile spasms. Cochrane Database Syst Rev. 2013;(6):CD001770. doi:https://doi.org/10.1 002/14651858.CD001770.pub3

2. Pavone P, Polizzi A, Marino SD, Corsello G, Falsaperla R, Marino S, et al. West syndrome: a comprehensive review. Neurol Sci. 2020;41(12):3547-3562. doi: https://doi.org/10.1007/s10072-020-04600-5

3. Wong M, Trevathan E. Infantile spasms. Pediatr Neurol. 2001 Feb;24(2):8998. doi: https://doi.org/10.1016/s0887-8994(00)00238-1. PMID: 11275456

4. Baram TZ. Pathophysiology of massive infantile spasms: perspective on the putative role of the brain adrenal axis. Ann Neurol. 1993;33(3):231-236. doi: https://doi.org/10.1002/ana.410330302

5. Riikonen R. Infantile Spasms: Outcome in Clinical Studies. Pediatr Neurol. 2020;108:54-64. doi:https://doi.org/10.1016/j.pediatrneurol.2020.01.015

6. Janicot R, Shao LR, Stafstrom CE. Infantile Spasms: An Update on Pre-Clinical Models and EEG Mechanisms. Children (Basel). 2020;7(1):5. Published 2020 Jan 6. doi:https://doi.org/10.3390/children7010005

7. Go CY, Mackay MT, Weiss SK, Stephens D, Adams-Webber T, Ashwal S, et al. Evidence-based guideline update: medical treatment of infantile spasms. Report of the Guideline Development Subcommittee of the American Academy of Neurology and the Practice Committee of the Child Neurology Society. Neurology. 2012;78(24):1974-1980. doi:https://doi.org/10.1212/WNL. 0b013e318259e2cf

8. Brunson KL, Avishai-Eliner S, Baram TZ. ACTH treatment of infantile spasms: mechanisms of its effects in modulation of neuronal excitability. Int Rev 
Neurobiol. 2002;49:185-197. doi:https://doi.org/10.1016/s0074-7742(02 149013-7

9. Hamano S, Yamashita S, Tanaka M, Yoshinari S, Minamitani M, Eto Y. Therapeutic efficacy and adverse effects of adrenocorticotropic hormone therapy in west syndrome: differences in dosage of adrenocorticotropic hormone, onset of age, and cause. J Pediatr. 2006;148(4):485-488. doi: https://doi.org/10.1016/j.jpeds.2005.11.041

10. Stanbury RM, Graham EM. Systemic corticosteroid therapy-side effects and their management. Br J Ophthalmol. 1998;82(6):704-708. doi:https://doi. org/10.1136/bjo.82.6.704

11. SPRAGUE RG. Cortisone and ACTH; a review of certain physiologic effects and their clinical implications. Am J Med. 1951;10(5):567-594. doi:https://doi. org/10.1016/0002-9343(51)90329-4

12. Jette N, Beghi E, Hesdorffer D, Moshé SL, Zuberi SL, Medina MT, et al. ICD coding for epilepsy: past, present, and future-a report by the International League Against Epilepsy Task Force on ICD codes in epilepsy. Epilepsia. 2015;56(3):348-355. doi:https://doi.org/10.1111/epi.12895

13. Urbina EM, Khoury PR, McCoy CE, Dolan LM, Daniels SR, Kimball TR. Triglyceride to $\mathrm{HDL}-\mathrm{C}$ ratio and increased arterial stiffness in children, adolescents, and young adults [published correction appears in Pediatrics. 2013 Oct;132(4):780]. Pediatrics. 2013;131(4):e1082-e1090. doi:https://doi. org/10.1542/peds.2012-1726

14. Chou JH, Roumiantsev S, Singh R. PediTools Electronic Growth Chart Calculators: Applications in Clinical Care, Research, and Quality Improvement. J Med Internet Res. 2020;22(1):e16204. Published 2020 Jan 30. doi:https://doi.org/10.2196/16204

15. Brooks J, Day S, Shavelle R, Strauss D. Low weight, morbidity, and mortality in children with cerebral palsy: new clinical growth charts. Pediatrics. 2011; 128(2):e299-e307. doi:https://doi.org/10.1542/peds.2010-2801

16. Barlow SE and the Expert Committee. Expert committee recommendations regarding the prevention, assessment, and treatment of child and adolescent overweight and obesity: summary report. Pediatrics 2007;120 Suppl. 164-192.

17. Shypailo RJ (2018) Age-based Pediatric Blood Pressure Reference Charts. Baylor College of Medicine, Children's Nutrition Research Center, Body Composition Laboratory. http://www.bcm.edu/bodycomplab/BPappZjs/ BPvAgeAPPz.html. Accessed 1 May 2021.

18. Flynn JT, Kaelber DC, Baker-Smith CM, Blowey D, Carroll AE, Daniels SR, et al. Clinical Practice Guideline for Screening and Management of High Blood Pressure in Children and Adolescents [published correction appears in Pediatrics. 2017 Nov 30;:] [published correction appears in Pediatrics. 2018 Sep;142(3):]. Pediatrics. 2017;140(3):e20171904. doi:https://doi.org/10.1542/ peds.2017-1904

19. Expert Panel on Integrated Guidelines for Cardiovascular Health and Risk Reduction in Children and Adolescents; National Heart, Lung, and Blood Institute. Expert panel on integrated guidelines for cardiovascular health and risk reduction in children and adolescents: summary report. Pediatrics. 2011;128 Suppl 5 213-256. doi:https://doi.org/10.1542/peds.2009-2107C

20. Pantoja-Torres B, Toro-Huamanchumo CJ, Urrunaga-Pastor D, GuarnizoPoma M, Lazaro-Alcantara H, Paico-Palacios S, et al. High triglycerides to $\mathrm{HDL}$-cholesterol ratio is associated with insulin resistance in normal-weight healthy adults. Diabetes Metab Syndr. 2019;13(1):382-388. doi:https://doi. org/10.1016/j.dsx.2018.10.006

21. Israel Central Bureau of Statistics (CBS); 2019. Characterization and Classification of Geographical Units by the Socio-Economic Level of the Population, 2015. https://www.cbs.gov.l/he/publications/DocLib/2019/1765_ socio_economic_2015/e_print.pdf. Accessed 20 Mar 2020.

22. Wanigasinghe J, Arambepola C, Sri Ranganathan S, Sumanasena S, Attanapola G. Randomized, Single-Blind, Parallel Clinical Trial on Efficacy of Oral Prednisolone Versus Intramuscular Corticotropin on Immediate and Continued Spasm Control in West Syndrome. Pediatr Neurol. 2015;53(3): 193-199. doi:https://doi.org/10.1016/.jpediatrneurol.2015.05.004

23. Partikian A, Mitchell WG. Major adverse events associated with treatment of infantile spasms. J Child Neurol. 2007;22(12):1360-1366. doi:https://doi.org/1 $0.1177 / 0883073807310988$

24. Markopoulou P, Papanikolaou E, Analytis A, Zoumakis E, Siahanidou T. Preterm Birth as a Risk Factor for Metabolic Syndrome and Cardiovascular Disease in Adult Life: A Systematic Review and Meta-Analysis. J Pediatr. 2019;210:69-80.e5. doi:https://doi.org/10.1016/j.jpeds.2019.02.041

25. de Jong F, Monuteaux MC, van Elburg RM, Gillman MW, Belfort MB. Systematic review and meta-analysis of preterm birth and later systolic blood pressure. Hypertension. 2012;59(2):226-234. doi:https://doi.org/10.11 61/HYPERTENSIONAHA.111.181784

26. McGarry L, Messer R, Cree-Green M, Ray K, Knupp K. Incidence of Hypertension Among Children Treated With Adrenocorticotropic Hormone (ACTH) or Prednisolone for Infantile Spasms. J Child Neurol. 2020;35(3):215220. doi:https://doi.org/10.1177/0883073819886244

27. Juhola J, Magnussen CG, Viikari JS, Kähönen M, Hutri-Kähönen N, Jula A, et al. Tracking of serum lipid levels, blood pressure, and body mass index from childhood to adulthood: the Cardiovascular Risk in Young Finns Study. J Pediatr. 2011;159(4):584-590. doi:https://doi.org/10.1016/j.jpeds.2011.03.021

28. Kannel WB, Vasan RS, Keyes MJ, Sullivan LM, Robins SJ. Usefulness of the triglyceride-high-density lipoprotein versus the cholesterol-high-density lipoprotein ratio for predicting insulin resistance and cardiometabolic risk (from the Framingham Offspring Cohort). Am J Cardiol. 2008;101(4):497-501. doi:https://doi.org/10.1016/j.amjcard.2007.09.109

29. Prasad M, Sara J, Widmer RJ, Lennon R, Lerman LO, Lerman A. Triglyceride and Triglyceride/ HDL (High Density Lipoprotein) Ratio Predict Major Adverse Cardiovascular Outcomes in Women With Non-Obstructive Coronary Artery Disease. J Am Heart Assoc. 2019;8(9):e009442. doi:https:// doi.org/10.1161/JAHA.118.009442

30. Hamed SA, Hamed EA, Kandil MR, El-Shereef HK, Abdellah MM, Omar H. Serum thyroid hormone balance and lipid profile in patients with epilepsy. Epilepsy Res. 2005;66(1-3):173-183. doi:https://doi.org/10.1016/j.eplepsyres.2 005.08.004

31. Vyas MV, Davidson BA, Escalaya L, Costella J, Saposnik G, Burneo JG. Antiepileptic drug use for treatment of epilepsy and dyslipidemia: Systematic review. Epilepsy Res. 2015;113:44-67. doi:https://doi.org/10.1016/ j.eplepsyres.2015.03.002

32. Kang HC, Chung DE, Kim DW, Kim HD. Early- and late-onset complications of the ketogenic diet for intractable epilepsy. Epilepsia. 2004;45(9):11161123. doi:https://doi.org/10.1111/j.0013-9580.2004.10004.x

33. Yilmaz E, Doşan Y, Gürgöze MK, Güngör S. Serum lipid changes during anticonvulsive treatment serum lipids in epileptic children. Acta Neurol Belg. 2001 Dec;101(4):217-20. PMID: 11851028

34. Cardamone M, Flanagan D, Mowat D, Kennedy SE, Chopra M, Lawson JA. Mammalian target of rapamycin inhibitors for intractable epilepsy and subependymal giant cell astrocytomas in tuberous sclerosis complex. J Pediatr. 2014;164(5):1195-1200. doi:https://doi.org/10.1016/j.jpeds.2013.12. 053

35. Sipola-Leppänen $M$, Vääräsmäki $M$, Tikanmäki $M$, Hovi P, Miettola S, Ruokonen A, et al. Cardiovascular risk factors in adolescents born preterm. Pediatrics. 2014;134(4):e1072-e1081. doi:https://doi.org/10.1542/peds.2013-41 86

\section{Publisher's Note}

Springer Nature remains neutral with regard to jurisdictional claims in published maps and institutional affiliations.

Ready to submit your research? Choose BMC and benefit from

- fast, convenient online submission

- thorough peer review by experienced researchers in your field

- rapid publication on acceptance

- support for research data, including large and complex data types

- gold Open Access which fosters wider collaboration and increased citations

- maximum visibility for your research: over $100 \mathrm{M}$ website views per year

At $\mathrm{BMC}$, research is always in progress.

Learn more biomedcentral.com/submission 